\title{
Antioxidant activities and phytochemical characteristics of extracts from Acacia confusa bark
}

\author{
Yu-Tang Tung ${ }^{\mathrm{a}}$, Jyh-Horng Wu ${ }^{\mathrm{b}}$, Chih-Yu Huang ${ }^{\mathrm{a}}$, Yueh-Hsiung Kuo ${ }^{\mathrm{c}, \mathrm{d}}$, \\ Shang-Tzen Chang ${ }^{\mathrm{a}, *}$ \\ ${ }^{a}$ School of Forestry and Resource Conservation, National Taiwan University, Taipei 106, Taiwan \\ ${ }^{\mathrm{b}}$ Department of Forestry, National Chung-Hsing University, Taichung 402, Taiwan \\ ${ }^{\mathrm{c}}$ Department of Chemistry, National Taiwan University, Taipei 106, Taiwan \\ ${ }^{\mathrm{d}}$ Tsuzuki Institute for Traditional Medicine, College of Pharmacy, China Medical University, Taichung 404, Taiwan
}

Received 2 October 2007; received in revised form 23 December 2007; accepted 3 January 2008

Available online 14 February 2008

\begin{abstract}
The present study was carried out to evaluate the antioxidant activities of bark extract of Acacia confusa and some of the isolated constituents from its ethyl acetate (EtOAc) fraction in various in vitro systems to gain mechanistic insights. Results from antioxidant assays together with authentic antioxidant standards revealed that EtOAc fraction showed strong superoxide radical scavenging activity, reducing power, and ferrous ion-chelating ability. Following an in vitro antioxidant activity-guided fractionation procedure, 16 constituents including 12 benzoic acids, three cinnamic acids and one lignans were isolated and identified from the EtOAc fraction. We also evaluated the structure-activity relationships of benzoic and cinnamic acid derivatives. Results obtained indicated that the bark extracts and the derived phytochemicals from $A$. confusa have a great potential to prevent disease caused by the overproduction of radicals and also it might be used as a potential source of natural antioxidant agent.
\end{abstract}

(C) 2008 Elsevier Ltd. All rights reserved.

Keywords: Acacia confusa; Antioxidant activity; Free radical; Phytochemical; Structure-activity relationships

\section{Introduction}

Acacia confusa Merr. (Leguminosae), a species indigenous to Taiwan, is widely distributed on the hills and lowlands of Taiwan, and it is traditionally used as a medicinal plant (Wu et al., 2005). An aqueous extract of $A$. confusa leaves was used in Taiwan for wound healing and antiblood-stasis (Kan, 1978). The crude extract of $A$. confusa bark contain a wide variety of phenolic compounds (Chang et al., 2001; Tung et al., 2007). Recent studies have shown that some phenolic compounds have anticancer, anticarcinogenic or antimutagenic activities (Behera et al., 2008; Papetti et al., 2006), and these bioactivities of phenolic

\footnotetext{
* Corresponding author. Tel.: +8862 33664626; fax: +886223654520. E-mail address: peter@ntu.edu.tw (S.-T. Chang).
}

compounds might be related to their antioxidant properties. In our previous studies, we found that the crude extracts of $A$. confusa bark and heartwood showed a high DPPH radical scavenging activity, and therefore it might be a good candidate for further development as antioxidant remedies (Chang et al., 2001; Wu et al., 2005; Tung et al., 2007).

Except the DPPH free radical scavenging activity reported in our previous short communication (Tung et al., 2007), the antioxidant activities of the crude extract, its derived fractions, and its constituents of $A$. confusa bark using different assay systems have not been comprehensively investigated. Mitchell et al. (1998) demonstrated that the assessment of antioxidant activities can be affected by many factors, such as $\mathrm{pH}$ value, varieties of solvents, free radicals as well as metal ions in the system analyzed. Actually, there is no universal method by which antioxidant 
activities can be measured accurately, because it may involve multiple reaction characters and mechanisms. Thus, in this study, a number of in vitro assays were performed to evaluate the antioxidant activities of ethanolic crude extracts and phytochemicals from $A$. confusa bark. Furthermore, the structure-activity relationships of isolated phytochemicals, benzoic and cinnamic acid derivatives were also investigated.

\section{Methods}

\subsection{Chemicals}

2,2'-Azinobis-(3-ethylbenzothiazoline-6-sulfonic acid) diammonium salt (ABTS), potassium persulfate, 1,1-diphenyl-2-picrylhydrazyl (DPPH), ascorbic acid, hypoxanthine, xanthine oxidase, nitroblue tetrazolium chloride (NBT), potassium dihydrogen phosphate $\left(\mathrm{KH}_{2} \mathrm{PO}_{4}\right)$, 2-thiobarbituric acid (TBA), trichloracetic acid (TCA), 3-(2-pyridyl)5,6-bis(4-phenyl-sulfonic acid)-1,2,4-triazine (Ferrozine), quercetin, and $(+)$-catechin were purchased from Sigma Chemical Co. (St. Louis, MO). All other unlabelled chemicals and reagents were purchased from Sigma Chemical Co. (St. Louis, MO).

\subsection{Plant material}

The bark of Acacia confusa was sampled from the experimental forest of National Taiwan University in Nan-Tou County. The species was identified by Mr. Sheng-You Lu of the Taiwan Forestry Research Institute, and a voucher specimen (AC001) was deposited at the School of Forestry and Resource Conservation, National Taiwan University. The materials were air dried at ambient temperature $\left(25^{\circ} \mathrm{C}\right)$.

\subsection{Extraction and isolation}

The dried samples $(7.2 \mathrm{~kg})$ were cut into small pieces and soaked in $70 \%$ ethanol at ambient temperature for 7 days. The extract was decanted, filtered under vacuum, concentrated in a rotary evaporator and then lyophilized. The resulting powder extract was then fractionated by liquid-liquid partition successively with EtOAc, $\mathrm{BuOH}$, and water. After removing the solvents used for the successive extractions, three soluble fractions were obtained. The yield of EtOAc, $\mathrm{BuOH}$, and water fractions are 333.5, 564.0, and $465.6 \mathrm{~g}$, respectively. The EtOAc fraction was separated by a Silica Gel 60 column (Merck, Darmstadt, Germany) eluted with a stepwise gradient of EtOAc/ $n$-hexane $2 / 98(\mathrm{v} / \mathrm{v})$ to $100 / 0(\mathrm{v} / \mathrm{v})$ to give $20 \mathrm{sub}$ fractions (EA1-EA20). Sixteen compounds were isolated and purified from EA12 to EA20 subfractions by HPLC based on an antioxidant activity-guided fractionation procedure. The structures of compounds 1-16 were identified by mass spectrometry and nuclear magnetic resonance analyses.

\subsection{Total antioxidant capacity by trolox equivalent antioxidant capacity (TEAC) assay}

TEAC was determined following the procedure described by $\mathrm{Re}$ et al. (1999) with slight modifications, using trolox as a standard. The $\mathrm{ABTS}^{+}$radical cation was generated by mixing ABTS stock solution $(7 \mathrm{mM}$ in water) with $2.45 \mathrm{mM}$ potassium persulfate. This mixture was kept at ambient temperature for 12-16 $\mathrm{h}$ until the reaction was complete and the absorbance was stable. The ABTS $^{++}$solution was diluted with water to give an absorbance value of $0.700 \pm 0.020$ at $730 \mathrm{~nm}$. The sample solution $(15 \mu \mathrm{l})$ was mixed with $1485 \mu \mathrm{l}$ of the $\mathrm{ABTS}^{+}$ solution. After $6 \mathrm{~min}$ of incubation at ambient temperature, the absorbance value of the mixture was measured at $730 \mathrm{~nm}$ in a Jasco V-550 UV-Vis spectrophotometer. Quercetin, a well-known antioxidant, was used as a positive control. Three replicates were made for each test sample. The TEAC of the sample was expressed as trolox equivalent in millimolars per $500 \mu \mathrm{g} / \mathrm{ml}$ (extracts) or $1 \mathrm{mM}$ (compounds).

\subsection{Superoxide radical scavenging assay (NBT assay)}

Measurement of superoxide radical scavenging activity was carried out according to the method of Chang et al. (2001). First, $20 \mu \mathrm{l}$ of $15 \mathrm{mM} \mathrm{Na} \mathrm{Na}_{2}$ EDTA in buffer ( $\left.50 \mathrm{mM} \mathrm{KH} \mathrm{KO}_{4} / \mathrm{KOH}, \mathrm{pH} 7.4\right), 50 \mu$ of $0.6 \mathrm{mM}$ nitroblue tetrazolium chloride (NBT) in buffer, $30 \mu \mathrm{l}$ of $3 \mathrm{mM}$ hypoxanthine in $50 \mathrm{mM} \mathrm{KOH}, 5 \mu \mathrm{l}$ of the test extracts or compounds in methanol and $145 \mu \mathrm{l}$ of buffer were mixed in 96-well microplates. The reaction was started by adding $50 \mu \mathrm{l}$ of xanthine oxidase in buffer ( 1 unit in $10 \mathrm{ml}$ buffer) to the mixture. The reaction mixture was incubated at ambient temperature, and the absorbance at $570 \mathrm{~nm}$ was determined every $1 \mathrm{~min}$ up to $8 \mathrm{~min}$ using the ELISA reader (Labsystems Multiskan, USA). (+)-Catechin and quercetin, well-known antioxidants, were used as positive controls. Three replicates were made for each test sample. The percent inhibition ratio was calculated according to the following equation: \% inhibition $=[$ (rate of control reaction - rate of sample reaction)/rate of control reaction] $\times 100$.

\subsection{Reducing power assay}

This assay was determined according to the method reported by Oyaizu (1986) with slight modifications. Briefly, $1 \mathrm{ml}$ of reaction mixture, containing $500 \mu \mathrm{l}$ of the test extracts or compounds in $500 \mu$ of phosphate buffer $(0.2 \mathrm{M}, \mathrm{pH}$ 6.6), was incubated with $500 \mu \mathrm{l}$ of potassium ferricyanide $(1 \%, \mathrm{w} / \mathrm{v})$ at $50{ }^{\circ} \mathrm{C}$ for $20 \mathrm{~min}$. The reaction was terminated by adding trichloroacetic acid $(10 \%, \mathrm{w} / \mathrm{v})$, then the mixture was centrifuged at $3000 \mathrm{rpm}$ for $10 \mathrm{~min}$. The supernatant solution $(500 \mu \mathrm{l})$ was mixed with distilled water $(500 \mu \mathrm{l})$ and $100 \mu \mathrm{l}$ of ferric chloride $(0.1 \%$, w/v) solution, then the optical density (OD) was measured at 
$700 \mathrm{~nm}$. Three replicates were made for each test sample. Increased OD value of the reaction mixture indicates increased reducing power.

\subsection{Determination of anti-FeCl 3 -ascorbic acid-stimulated lipid peroxidation in liposomes}

This assay was determined according to the method reported by Duh et al. (1999) with slight modifications. Lecithin $(300 \mathrm{mg})$ was sonicated in an ultrasonic cleaner in $30 \mathrm{ml}$ phosphate buffer $(50 \mathrm{mM}, \mathrm{pH} 7.4)$ for $2 \mathrm{~h}$ at ice cold temperature. Five hundred microliters of sonicated solution (10 mg liposome in $1 \mathrm{ml}$ phosphate buffer) were incubated with the test extracts $(100 \mu l)$ in the presence of $1 \mathrm{mM} \mathrm{FeCl}_{3}$ $(200 \mu \mathrm{l})$ and $1 \mathrm{mM}$ ascorbic acid $(200 \mu \mathrm{l})$ at $37^{\circ} \mathrm{C}$ for $1 \mathrm{~h}$. The reaction was terminated by addition of $500 \mu$ trichloroacetic acid $(20 \%, \mathrm{w} / \mathrm{v})$ and $500 \mu \mathrm{l}$ thiobarbituric acid $(1 \%$, $\mathrm{w} / \mathrm{v})$, then the solution was heated at $100{ }^{\circ} \mathrm{C}$. After $15 \mathrm{~min}$, the color of the malondialdehyde (MDA)-TBA complex was measured at $532 \mathrm{~nm}$. Quercetin was used as a positive control. Three replicates were made for each test sample. The inhibition ratio (\%) was calculated as follows: $\%$ inhibition $=[$ absorbance of control - absorbance of test sample)/absorbance of control $] \times 100$.

\subsection{Ferrous ion-chelating ability assay}

The ferrous ion-chelating potential of the test samples was evaluated following the method of Dinis et al. (1994) with slight modifications. Briefly, $200 \mu 1$ of test extracts in methanol (final concentrations were 156.25, 312.5, 625, 1250 , and $2500 \mu \mathrm{g} / \mathrm{ml}$, respectively) and $740 \mu 1$ methanol were added to $20 \mu \mathrm{l}$ of $2 \mathrm{mM} \mathrm{FeCl}_{2}$. The reaction was initiated by adding $40 \mu \mathrm{l}$ of $5 \mathrm{mM}$ ferrozine. The mixture was shaken vigorously and rested at ambient temperature for $10 \mathrm{~min}$. Absorbance of the solution was then measured at $562 \mathrm{~nm}$. Quercetin was used as a positive control. Three replicates were made for each test sample. The percent of inhibition of ferrozine- $\mathrm{Fe}^{2+}$ complex formation was calculated according to the following equation: \% inhibition $=[$ absorbance of control - absorbance of sample reaction)/absorbance of control] $\times 100$.

\subsection{1,1-Diphenyl-2-picrylhydrazyl (DPPH) assay}

The DPPH radical scavenging activity of phytocompounds from $A$. confusa bark was examined according to the method reported by Chang et al. (2001). Briefly, $10 \mu \mathrm{l}$ of compounds in methanol (final concentrations were 1 , $5,10,25,50$, and $100 \mu \mathrm{g} / \mathrm{ml}$, respectively) were mixed with $90 \mu \mathrm{l}$ of $50 \mathrm{mM}$ Tris- $\mathrm{HCl}$ buffer (pH 7.4) and $200 \mu 1$ of $0.1 \mathrm{mM}$ DPPH-ethanol solution. After $30 \mathrm{~min}$ of incubation at ambient temperature, the reduction of the DPPH free radical was measured by reading the absorbance at $517 \mathrm{~nm}$ using the ELISA reader. (+)-Catechin was used as a positive control. Three replicates were made for each test sample. The inhibition ratio (\%) was calculated accord- ing to the following equation: $\%$ inhibition $=[($ absorbance of control - absorbance of sample)/absorbance of control] $\times$ 100 .

\section{Results and discussion}

\subsection{TEAC values of A. confusa bark}

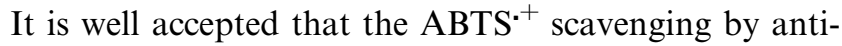
oxidants is attributable to their hydrogen donating ability. $A$. confusa bark extract and its derived fractions were examined for their free radical scavenging activity against $\mathrm{ABTS}^{+}$cation radical. These results were compared to the free radical scavenging activity of trolox. The TEAC values for $0.5 \mathrm{mg} / \mathrm{ml}$ quercetin, crude extract, EtOAc, $\mathrm{BuOH}$, and water fractions were 4.0, 1.8, 2.0, 1.6, and $1.4 \mathrm{mM}$, respectively. Among the fractions tested, EtOAc fraction was found to be the best, followed by $\mathrm{BuOH}$ fraction and water fraction.

\subsection{Superoxide radical scavenging activity of A. confusa bark}

Results from superoxide radical scavenging assay showed that, at the $25 \mu \mathrm{g} / \mathrm{ml}$ sample concentration, inhibitory effect of $A$. confusa bark extract and its derived fractions decreased in the following order: EtOAc fraction $(85.3 \%)>\mathrm{BuOH}$ fraction $(79.8 \%)>$ water fraction $(74.4 \%)>$ crude extract $(70.4 \%)$. The concentration required to inhibit $50 \%$ radical scavenging effect $\left(\mathrm{IC}_{50}\right)$ was determined from the results of a series of concentrations tested. A lower $\mathrm{IC}_{50}$ value corresponds to a greater scavenging activity. The $\mathrm{IC}_{50}$ values of quercetin, crude, EtOAc, BuOH, and water fractions were 2.8, 9.5, 4.7, 5.0 , and $8.3 \mu \mathrm{g} / \mathrm{ml}$, respectively, revealing that the EtOAc fraction possessed the highest superoxide radical scavenging activity.

\subsection{Reducing power of A. confusa bark}

As shown in Fig. 1, the reducing power of the test samples correlated well with increasing concentrations, and all the crude extract and its derived fractions, except for water fraction, exhibited a similar reducing power. At the concentration of $25 \mu \mathrm{g} / \mathrm{ml}$, the $\mathrm{OD}$ values of crude extract, $\mathrm{BuOH}$ fraction, EtOAc fraction, and water fraction were 0.81, $0.78,0.76$, and 0.61 , respectively. However, the reducing power of quercetin was relatively more pronounced than that of all the test samples.

\subsection{Inhibition activity of lipid peroxidation in liposomes of A. confusa bark}

Results shown in Fig. 2 revealed that the crude extract and its derived fractions have an excellent activity in suppressing lipid peroxidation. $\mathrm{BuOH}$ fraction had better inhibitory effect than quercetin, $49.2 \%$ of the inhibitory 


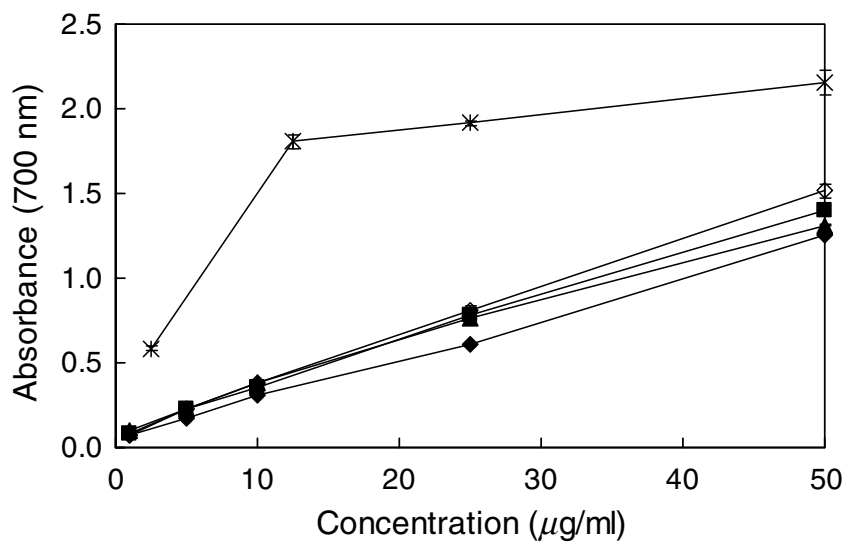

Fig. 1. Reducing power of ethanolic extract and its fractions from the bark of $A$. confusa: $(\diamond)$ crude extract, $(\boldsymbol{\Delta})$ EtOAc fraction, $(\boldsymbol{\square}) n$-butanol fraction, $(\diamond)$ water fraction, $(\times)$ quercetin. Results are mean $\pm \operatorname{SD}(n=3)$.

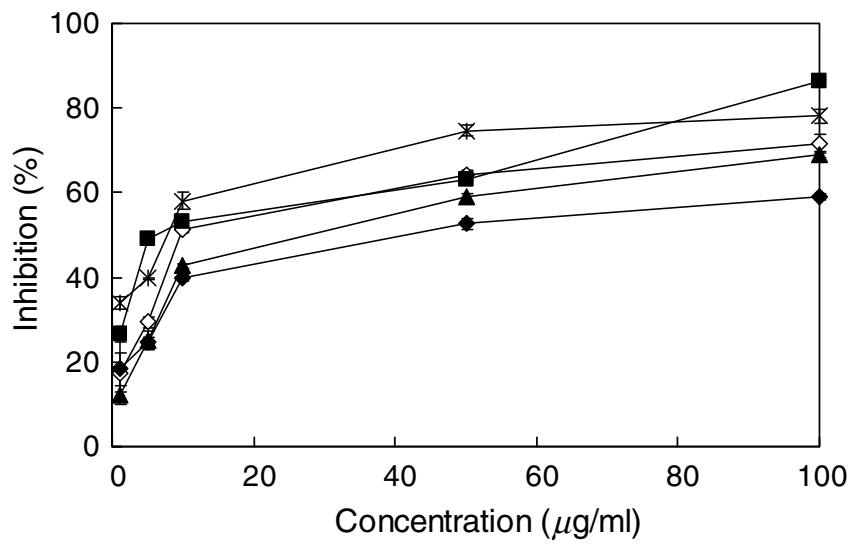

Fig. 2. Inhibition activity of lipid peroxidation in liposomes of ethanolic extract and its fractions from the bark of $A$. confusa: $(\diamond)$ crude extract, $(\mathbf{\Delta})$ EtOAc fraction, $(\boldsymbol{\square}) n$-butanol fraction, $(\downarrow)$ water fraction, $(\times)$ quercetin. Results are mean $\pm \mathrm{SD}(n=3)$.

activity of lipid peroxidation was observed at the concentration of $5 \mu \mathrm{g} / \mathrm{ml}$. The $\mathrm{IC}_{50}$ values of quercetin, crude extract, EtOAc, $\mathrm{BuOH}$, and water fractions were 7.8, 9.7, 28.1, 6.0, and $41.5 \mu \mathrm{g} / \mathrm{ml}$, respectively. Among them, the $\mathrm{BuOH}$ fraction was found to be the best.

\subsection{Ferrous ion-chelating effect of A. confusa bark}

The chelating effects of the test samples on ferrous ions are shown in Fig. 3. It was noted that the chelating ability of tested samples increased as a function of concentration. On the other hand, the crude extract and its derived fractions had an excellent chelating ability, which was even much better than quercetin. The $\mathrm{IC}_{50}$ values of the crude extract, EtOAc fraction, $\mathrm{BuOH}$ fraction, and water fraction were 898.6, 253.0, 271.2, and $2185.6 \mu \mathrm{g} / \mathrm{ml}$, respectively. Even with a dosage as low as $625 \mu \mathrm{g} / \mathrm{ml}$, the chelating ability of the EtOAc and $\mathrm{BuOH}$ fraction reached over $80 \%$ in this assay. Surprisingly, quercetin did not show any chelating ability, which may be due to the presence of iron(II) chloride in the system to induce its degradation. These results

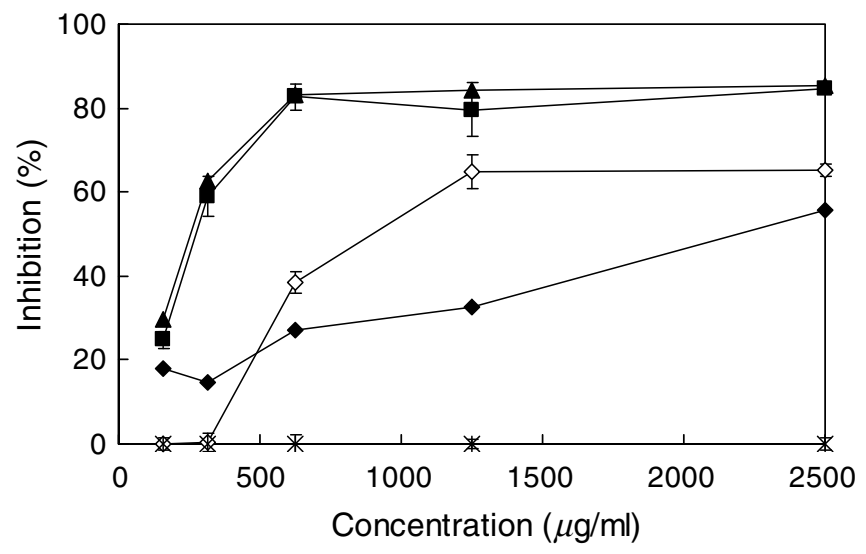

Fig. 3. Ferrous ion-chelating ability of ethanolic extract and its fractions from the bark of $A$. confusa: $(\diamond)$ crude extract, $(\boldsymbol{\Delta})$ EtOAc fraction, (घ) $n$-butanol fraction, $(\diamond)$ water fraction, $(\times)$ quercetin. Results are mean $\pm \mathrm{SD}(n=3)$.

revealed that $A$. confusa bark extract had an effective capacity for iron binding, suggesting that its action as peroxidation protector might be related to its iron-binding capacity.

\subsection{Isolation and identification of phytocompounds from A. confusa bark}

According to the aforesaid results, the EtOAc fraction showed strong superoxide radical scavenging activity, reducing power, and ferrous ion-chelating ability. These results indicated that antioxidant activities of $A$. confusa bark have been effectively enriched in the EtOAc fraction. The phytocompounds of EtOAc fraction were purified and determined by using HPLC, MS, and 1D- and 2D- NMR spectroscopy. Sixteen phytocompounds (1-16) were identified as 4-hydroxybenzoic acid (1) (Lo et al., 2002), 4-hydroxybenzoic acid ethyl ester (2) (Owen et al., 2003), 3,4-dihydroxybenzoic acid (3) (Flamini et al., 2001), 3,4-dihydroxybenzoic acid methyl ester (4), 3,4-dihydroxybenzoic acid ethyl ester (5) (Baderschneider and Winterhalter, 2001), 3,4-dihydroxybenzoic acid butyl ester (6), 3hydroxy-4-methoxybenzoic acid (7) (Ding et al., 2000), 4-hydroxy-3-methoxybenzoic acid (8) (Lee et al., 2004), 4-hydroxy-3,5-dimethoxybenzoic acid (9), 4-hydroxy-3,5dimethoxybenzoic acid ethyl ester (10), 3,4,5-trihydroxybenzoic acid (11) (Chen et al., 1999), 3,4,5-trihydroxybenzoic acid ethyl ester (12), 3,4-dihydroxy-trans-cinnamic acid (13) (Islam et al., 2002), 3,4-dihydroxy-trans-cinnamic acid ethyl ester (14), 3,4-dihydroxy-trans-cinnamic acid pentyl ester (15), and (-)-lyoniresinol (16) (Hanawa et al., 1997). All the ${ }^{1} \mathrm{H},{ }^{13} \mathrm{C}$ NMR, and MS spectral data of compounds 1-16 were in good agreement with the published literature values. This is the first report of cinnamic acid and lignan skeletons in the $A$. confusa.

\subsection{Antioxidant activities of isolated compounds}

As shown in Table 1, the antioxidant activities of sixteen phytocompounds were evaluated by DPPH, NBT, TEAC, 
Table 1

Antioxidant activities of phytocompounds from the bark of $A$. confusa

\begin{tabular}{lllll}
\hline Compounds & \multicolumn{2}{l}{$\mathrm{IC}_{50}$ value $(\mu \mathrm{g} / \mathrm{ml}$ or $\mu \mathrm{M})$} & $\begin{array}{l}\text { TEAC } \\
(\mathrm{mM})\end{array}$ & $\begin{array}{l}\text { Reducing power } \\
\left(\mathrm{OD}_{700}\right)^{\mathrm{b}}\end{array}$ \\
\cline { 2 - 3 } $\mathrm{DPPH}^{-}$ & $\mathrm{O}_{2}{ }^{-}$ & & \\
\hline 1 & $>100$ & $>100$ & 0.1 & 0.02 \\
2 & $>100$ & $>100$ & 0.1 & 0.02 \\
3 & $1.8(11.7)^{\mathrm{a}}$ & $7.1(46.1)$ & 2.6 & 0.66 \\
4 & $4.0(23.8)$ & $23.7(141.0)$ & 3.1 & 0.65 \\
5 & $2.0(11.0)$ & $3.8(20.9)$ & 2.4 & 0.58 \\
6 & $4.3(20.5)$ & $30.2(143.8)$ & 2.6 & 0.60 \\
7 & $85.1(506.5)$ & $>100$ & 0.2 & 0.04 \\
8 & $22.5(133.9)$ & $>100$ & 0.3 & 0.03 \\
9 & $3.5(17.7)$ & $>100$ & 4.1 & 0.39 \\
10 & $3.8(16.8)$ & $>100$ & 3.9 & 0.40 \\
11 & $1.4(8.2)$ & $2.1(12.4)$ & 5.2 & 1.14 \\
12 & $2.3(11.6)$ & $3.2(16.2)$ & 4.9 & 1.09 \\
13 & $4.9(27.2)$ & $4.0(22.2)$ & 2.3 & 0.67 \\
14 & $5.9(28.4)$ & $3.8(18.3)$ & 2.0 & 0.67 \\
15 & $8.3(33.2)$ & $5.9(23.6)$ & 2.2 & 0.65 \\
16 & $7.3(17.4)$ & $>100$ & 1.9 & 0.50 \\
$(+)-C a t e c h i n$ & $3.3(11.4)$ & $2.8(9.7)$ & - & 0.89 \\
Quercetin & - & - & 4.0 & - \\
\hline a (): $\mu$ M. & &
\end{tabular}

and reducing power assays. In terms of the $\mathrm{IC}_{50}$ values, the compounds can be ranked in the following descending order: $\quad 11>3>5>12>9>10>4>6>13>14>16>$ $\mathbf{1 5}>\mathbf{8}>\mathbf{7}>\mathbf{1}=\mathbf{2}$ for DPPH free radical scavenging activity. The results indicated that compounds 3-6 and 9-16 were most active and their $\mathrm{IC}_{50}$ values ranged from 1.4 to $8.3 \mu \mathrm{g} / \mathrm{ml}$; while compounds 1 and 2 found to be least active, with the $\mathrm{IC}_{50}$ values higher than $100 \mu \mathrm{g} / \mathrm{ml}$. On the other hand, the decreasing antioxidant activity order of phytocompounds in the NBT assay can be ranked as $11>12>5=14>13>15>3>4>6>1=2=7=8=$ $\mathbf{9}=\mathbf{1 0}=\mathbf{1 6}$. The results indicated that compounds $\mathbf{3}, \mathbf{5}$, and 11-15 (the $\mathrm{IC}_{50}$ values were less than $10 \mu \mathrm{g} / \mathrm{ml}$ ) were most active than others, while compounds $\mathbf{1}, \mathbf{2}, \mathbf{7 - 1 0}$, and 16 were least active (the $\mathrm{IC}_{50}$ values were higher than 100 $\mu \mathrm{g} / \mathrm{ml})$. Furthermore, TEAC values of 16 phytocompounds were obtained by inhibiting $\mathrm{ABTS}^{+}$. The best antioxidant activity obtained from TEAC assay was found in 11, followed by 12, 9, 10, 4, 3, 6, 5, 13, 15, 14, 16, 8, 7, 1, and 2. The reducing power of compounds at $50 \mu \mathrm{M}$ is as follows: $11>12>13=14>3>4=15>6>5>16>10>$ $\mathbf{9}>\mathbf{7}>\mathbf{8}>\mathbf{1}=\mathbf{2}$. The above results were compared with standard antioxidant, $(+)$-catechin, and it had $\mathrm{IC}_{50}$ values 3.3 and $2.8 \mu \mathrm{g} / \mathrm{ml}$ in the DPPH and NBT assays. It is interesting to note that 3,4,5-trihydroxybenzoic acid (11) had $\mathrm{IC}_{50}$ values of 1.4 and $2.1 \mu \mathrm{g} / \mathrm{ml}$ in the DPPH and NBT assays. Therefore, 3,4,5-trihydroxybenzoic acid clearly is responsible for the excellent antioxidant activity.

\subsection{Structure-activity relationships of benzoic and cinnamic acids derivatives from A. confusa bark}

The study also investigated the structure-activity relationships of benzoic and cinnamic acid derivatives (com- pounds 1-15) based on their antioxidant activities. Accordingly, among DPPH, NBT, TEAC, and reducing power assays, the decreasing order of antioxidant activities of substituted benzoic acids were as follows: 3,4,5-trihydroxybenzoic acid (11) >3,4-dihydroxybenzoic acid (3) $>4$-hydroxybenzoic acid (1). It is clear that compounds with three hydroxyl groups on the phenyl ring of phenolic acids had the highest antioxidant activities. The loss of one hydroxyl group decreased activity slightly, while the loss of two hydroxyl groups decreased activity significantly. Similarly, Fukumoto and Mazza (2000) also showed that an increase in the number of hydroxyl groups led to higher antioxidant activities. In addition, Dziedzic and Hudson (1983) concluded that at least two hydroxyl groups were required for antioxidant activities of phenolic acids. Besides, phenyl ring with the same number of hydroxyl groups, such as 3,4-dihydroxybenzoic acid (3), 3,4-dihydroxybenzoic acid methyl ester (4), 3,4-dihydroxybenzoic acid ethyl ester (5), and 3,4-dihydroxybenzoic acid butyl ester (6) or 3,4-dihydroxy-trans-cinnamic acid (13), 3,4dihydroxy-trans-cinnamic acid ethyl ester (14), and 3,4dihydroxy-trans-cinnamic acid pentyl ester (15) exhibited the similar antioxidant activities. Furthermore, 4-hydroxy-3-methoxybenzoic acid (8) exhibits higher antioxidant activity than 3-hydroxy-4-methoxybenzoic acid (7). This result suggests that the position of the hydroxyl group is also an important factor responsible for this behavior. For the phenyl ring with a hydroxyl group and different number of methoxyl groups, the decreasing order of activities found was as follows: 4-hydroxy-3,5-dimethoxybenzoic acid (9) >4-hydroxy-3-methoxybenzoic acid (7) >4-hydroxybenzoic acid (1). This result is in accordance with the conclusions obtained by Chaillou and Nazareno (2006). Thus, it was found that the antioxidant efficiency of monophenols is strongly enhanced by the introduction of second hydroxyl group and is increased by one or two methoxyl substitutions in the ortho position. On the other hand, to understand the influence of acyl chain lengths of monophenols on their antioxidant activities, compounds 3-6 (benzoic acids) and compounds 13-15 (cinnamic acids) were further investigated. Accordingly, as shown in Table 1 , results revealed that acyl chain lengths of benzoic acids or cinnamic acids had no significant influence on their antioxidant activities.

\section{Conclusions}

The extract of $A$. confusa bark exhibited the strong antioxidant activity in the tested in vitro assays. Some constituents of $A$. confusa bark extracts in DPPH, NBT, TEAC, and reducing power assays were found to be more effective than that of the crude extract. This indicates that the bark extract from $A$. confusa or its derived phytocompounds have a great potential to prevent disease caused by the overproduction of radicals. These results can be useful as a starting point of view for further applications of 
A. confusa bark or its constituents in pharmaceutical preparations after performing clinical in vivo researches.

\section{Acknowledgements}

We thank the National Science Council for the financial support (NSC95-2313-B-002-032) and the experimental forest of National Taiwan University for providing $A$. confusa materials, as well as Ms. Shou-Ling Huang (Department of Chemistry, National Taiwan University) for NMR spectral analyses.

\section{References}

Baderschneider, B., Winterhalter, P., 2001. Isolation and characterization of novel benzoates, cinnamates, flavonoids, and lignans from Riesling wine and screening for antioxidant activity. J. Agric. Food Chem. 49, 2788-2798.

Behera, B.C., Verma, N., Sonone, A., Makhija, U., 2008. Antioxidant and antibacterial properties of some cultured lichens. Bioresour. Technol. 99, 776-784.

Chaillou, L.L., Nazareno, M.A., 2006. New method to determine antioxidant activity of polyphenols. J. Agric. Food Chem. 54, 83978402.

Chang, S.-T., Wu, J.-H., Wang, S.-Y., Kang, P.-L., Yang, N.-S., Shyur, L.-F., 2001. Antioxidant activity of extracts from Acacia confusa bark and heartwood. J. Agric. Food Chem. 49, 3420-3424.

Chen, Y., Wang, M., Rosen, R.T., Ho, C.T., 1999. 2,2-Diphenyl-1picrylhydrazyl radical-scavenging active components from Polygonum multiflorum Thund. J. Agric. Food Chem. 47, 2226-2228.

Ding, H.-Y., Lin, H.-C., Teng, C.-M., Wu, Y.-C., 2000. Phytochemical and pharmacological studies on Chinese Paeonia species. J. Chin. Chem. Soc. 47, 381-388.

Dinis, T.C.P., Madeira, V.M.C., Almeida, L.M., 1994. Action of phenolic derivatives (acetaminophen, salicylate, and 5-aminosalicylate) as inhibitors of membrane lipid peroxidation and as peroxyl radical scavengers. Arch. Biochem. Biophys. 315, 161-169.

Duh, P.D., Tu, Y.Y., Yen, G.C., 1999. Antioxidant activity of water extract of harng Jyur (Chrysanthemum morifolium Ramat). Lebensm.Wiss. U.-Technol. 32, 269-277.
Dziedzic, S.Z., Hudson, B.J.F., 1983. Hydroxy isoflavones as antioxidants for edible oils. Food Chem. 11, 161-166.

Flamini, G., Antognoli, E., Morelli, I., 2001. Two flavonoids and other compounds from the aerial parts of Centaurea bracteata from Italy. Phytochemistry 57, 559-564.

Fukumoto, L.R., Mazza, G., 2000. Assessing antioxidant and prooxidant activities of phenolic compounds. J. Agric. Food Chem. 48, 3597-3604.

Hanawa, F., Shiro, M., Hayashi, Y., 1997. Heartwood constituents of Betula maximowicziana. Phytochemistry 45, 589-595.

Islam, M.S., Yoshimoto, M., Yahara, S., Okuno, S., Ishiguro, K., Yamakawa, O., 2002. Identification and characterization of foliar polyphenolic composition in sweet potato (Ipomoea batatas L.) genotypes. J. Agric. Food Chem. 50, 3718-3722.

Kan, W.-S., 1978. Leguminosae. In: Kan, W.-S. (Ed.), Manual of Medicinal Plants in Taiwan, vol. 2. National Research Institute of Chinese Medicine, Taipei, Taiwan, pp. 239-240.

Lee, C.K., Lu, C.K., Kuo, Y.H., Chen, J.Z., Sun, G.Z., 2004. New prenylated flavones from the roots of Ficus beecheyana. J. Chin. Chem. Soc. $51,437-442$.

Lo, W.L., Chang, F.R., Hsieh, T.J., Wu, Y.C., 2002. The constituents of Euchresta formosana. J. Chin. Chem. Soc. 49, 421-426.

Mitchell, J.H., Gardner, P.T., McPhail, D.B., Morrice, P.C., Collins, A.R., Duthie, G.G., 1998. Antioxidant efficacy of phytoestrogens in chemical and biological model systems. Arch. Biochem. Biophys. 360, $142-148$

Owen, C., James, K., Sampson, L., Ahmed, S., 2003. Synthesis and biochemical evaluation of some novel benzoic acid based esters aspotential inhibitors of oestrone sulphatase. J. Pharm. Pharmacol. 55, 85-93.

Oyaizu, M., 1986. Studies on product of browning reaction prepared from glucosamine. Jpn. J. Nutr. 44, 307-315.

Papetti, A., Daglia, M., Aceti, C., Quaglia, M., Gregotti, C., Gazzani, G., 2006. Isolation of an in vitro and ex vivo antiradical melanoidin from roasted barley. J. Agric. Food Chem. 54, 1209-1216.

Re, R., Pellegrini, N., Proteggente, A., Pannala, A., Yang, M., Rice-Evans, C., 1999. Antioxidant activity applying an improved ABTS radical cation decolorization assay. Free Radical Biol. Med. 26, 1231-1237.

Tung, Y.-T., Wu, J.-H., Kuo, Y.-H., Chang, S.-T., 2007. Antioxidant activities of natural phenolic compounds from Acacia confusa bark. Bioresource Technol. 98, 1120-1123.

Wu, J.-H., Tung, Y.-T., Wang, S.-Y., Shyur, L.-F., Kuo, Y.-H., Chang, S.-T., 2005. Phenolic antioxidants from the heartwood of Acacia confusa. J. Agric. Food Chem. 53, 5917 -5921. 